\title{
Current indications for the use of clindamycin: A critical review
}

\author{
Marek Smieja MD FRCPC DTM\&H
}

M Smieja. Current indications for the use of clindamycin: A critical review. Can J Infect Dis 1998;9(1):22-28.

OBJECTIVES: To review the literature and develop evidence-based guidelines for the use of the antibiotic clindamycin. DATA SOURCES: A search of the MEDLINE database for randomized clinical trials, cohort studies and review articles that examine the therapeutic use or potential adverse effects of clindamycin was undertaken for the years 1966 to 1996. In addition, relevant citations obtained from the references cited in the identified reviews, book chapters and antibiotic guidelines were included.

DATA EXTRACTION: Selected articles examining the indications for or adverse effects from the prophylactic or therapeutic use of clindamycin were selected. A level of evidence was assigned to the indication according to published criteria.

DATA SYNTHESIS AND CONCLUSIONS: Randomized clinical trials (level 1 evidence) support the use of clindamycin in a number of common conditions, including preoperative prophylaxis, intra-abdominal infections, recurrent group A streptococcal pharyngitis, Chlamydia trachomatis cervicitis and anaerobic lung infections. Cohort studies (level 2 evidence) support the use of clindamycin for bone and soft tissue infections. Expert opinion (level 3 evidence) supports the use of clindamycin for invasive group A streptococcal infection and the treatment of diabetic foot infections. Clindamycin's disadvantages are its high cost, the common occurrence of rash and the predisposition of patients taking clindamycin to Clostridium difficile-associated colitis. Based on cohort studies, the risk of severe diarrhea in out-patients is as low as one per 1000 , but the risk of in-patients acquiring C difficile colonization may be as high as $30 \%$.

Key Words: Antibiotic, Clindamycin, Guidelines, Therapeutic use

\section{Indications actuelles de la clindamycine : revue critique}

OBJECTIFS : Passer en revue la littérature et mettre au point des directives fondées sur les preuves pour l'utilisation de la clindamycine.

SOURCES DE DONNÉES : Une interrogation du réseau MEDLINE sur les effets cliniques randomisés, les études de cohorte et les articles de synthèse qui se sont penchés sur l'emploi thérapeutique ou les effets indésirables potentiels de la clindamycine a été entreprise pour les années 1966 à 1996. De plus, toute citation pertinente obtenue à partir de références citées dans les revues, les livres et les directives d'antibiothérapie identifiées sont incluses.

EXTRACTION DES DONNÉES : Les articles sélectionnés portant sur les indications ou les réactions indésirables de l'emploi prophylactique ou thérapeutique de la clindamycine ont été choisis. Un degré de preuve a été assigné à l'indication, selon les critères publiés.

SYNTHÈSE DES DONNÉES ET CONCLUSIONS : Les essais cliniques randomisés (preuve de degré 1) appuient l'emploi de la clindamycine pour un certain nombre d'affections courantes, notamment en prophylaxie préopératoire, dans les infections intra-abdominales, dans la pharyngite récurrente au streptocoque du groupe A, dans la cervicite à Chlamydia trachomatis et les infections pulmonaires anaérobies. Les études de cohortes (preuve de degré 2) appuient l'emploi de clindamycine pour les infections des os et des tissus mous. De l'opinion des experts (preuve de degré 3 ), la clindamycine est indiquée dans les infections au streptocoque du groupe A invasives et dans le traitement des infections du pied

Winner of the Canadian Infectious Diseases Society/Canadian Journal of Infectious Diseases Trainee Review Article Award Departments of Medicine and Pathology, McMaster University, Hamilton, Ontario

Correspondence: Dr M Smieja, c/o Room 2N29, McMaster Unverisity Medical Centre, 1200 Main Street West, Hamilton, Ontario L8N $3 Z 5$. Telephone 905-521-2100, ext 6307, fax 905-521-5099, e-mail smiejam@fhs.csu.mcmaster.ca 
diabétique. Les inconvénients de la clindamycine sont : son coût élevé, la fréquence des éruptions cutanées et la prédisposition des patients sous clindamycine à développer une colite associée à Clostridium difficile. Sur la base des études de cohortes, le risque de diarrhée grave chez les patients non hospitalisés n'est que de un par mille, mais le risque de colonisation des patients hospitalisés par $C$. difficile pourrait atteindre $30 \%$.

$\mathrm{C}$ indamycin is a lincosamide antibiotic, developed in 1966 by chemically modifying the naturally occurring lincomycin. In vitro, its spectrum of activity includes staphylococci, streptococci and pneumococci, most anaerobic bacteria (including over $90 \%$ of Bacteroides fragilis), Chlamydia trachomatis and certain protozoa. Like penicillin, it has activity against group A and B streptococci, microaerophilic streptococci and most Streptococcus pneumoniae. It does not, however, have activity against the enterococci. Like cloxacillin and the cephalosporins, clindamycin possesses activity against Staphylococcus aureus. It has broader anaerobic coverage than most cephalosporins, but has virtually no activity against aerobic Gram-negative bacteria. With its excellent activity against both Gram-positive cocci and Gram-positive or -negative anaerobes, clindamycin has a role in the treatment of head and neck, respiratory, bone and soft tissue, abdominal, and pelvic infections (1-4).

Clindamycin acts by inhibiting bacterial protein synthesis at the level of the 50S ribosome. As a result, it exerts a prolonged postantibiotic effect. It may decrease toxin production and increase microbial opsonization and phagocytosis even at subinhibitory concentrations. Although chemically dissimilar to erythromycin and the macrolide antibiotics, in vitro antagonism occurs as a result of a similar site of binding and mechanism of action.

Clindamycin is purportedly well absorbed (90\%) from the gastrointestinal tract, and high concentrations are achieved in most tissues including neutrophils, bone (60\%) and joints $(85 \%)$ but not in the central nervous system. Recent data indicate that the true absorption of clindamycin may be closer to $50 \%$, and, paradoxically, higher levels are obtained in patients with advanced human immunodeficiency virus (HIV) infection (75\% absorption), possibly as a result of decreased hepatic metabolism (5). Previous studies indicating high absorption may have been measuring an inactive metabolite. The drug is metabolized and excreted by the liver, and dose modifications are recommended for hepatic failure or concomitant renal and hepatic dysfunction. The half-life is 2 to $2.5 \mathrm{~h}$, but may be prolonged to 8 to $12 \mathrm{~h}$ in patients with severe liver disease (2). Biliary excretion of active drug and metabolites results in prolonged activity of clindamycin within the intestine, with effects on gastrointestinal flora for up to two weeks. This may be relevant to both the development and duration of Clostridium difficile-associated colitis. Clindamycin is available as oral tablets (150 and $300 \mathrm{mg}$ ), parenteral injection (intramuscular or intravenous), and topical and vaginal formulations. Usual parenteral doses are $600 \mathrm{mg}$ every 6 to $8 \mathrm{~h}$ to $900 \mathrm{mg}$ every $8 \mathrm{~h}$. Typical oral doses are 150 to $450 \mathrm{mg}$ qid. Topical formulations include a $2 \%$ ointment and $2 \%$ vaginal gel.

This paper reviews the literature for evidence of the efficacy of clindamycin in various clinical conditions. Computerized searches of the MEDLINE database (1966 to 1996) were performed to identify primary and review articles about the therapeutic use of clindamycin. The articles were supplemented by examining cited references, reviewing standard textbooks of infectious diseases and clinical pharmacology, and consulting existing infectious diseases treatment guidelines.

In the following sections the evidence for using clindamycin in specific conditions will be reviewed, grouped according to anatomical location and clinical syndromes. In the individual patient, indications for using clindamycin based on expert opinion and evidence of efficacy from clinical trials must be weighed against the potential side effects and costs of the regimens studied. Factors such as out-patient status, allergic reactions, tolerability, cost and potential adverse effects must all be considered (6).

\section{SKIN AND SOFT TISSUE INFECTIONS}

With its activity against $S$ aureus, streptococci and anaerobes, clindamycin has been found effective for various skin and soft tissue infections. Median minimum inhibitory concentration (MIC) for group A streptococci was $0.04 \mu \mathrm{g} / \mathrm{mL}$ for clindamycin (range 0.02 to $0.1 \mu \mathrm{g} / \mathrm{mL}$ ), compared with $0.05 \mu \mathrm{g} / \mathrm{mL}$ for penicillin $\mathrm{G}(1)$. For $S$ aureus, median MIC was $0.1 \mu \mathrm{g} / \mathrm{mL}$ compared with $0.4 \mu \mathrm{g} / \mathrm{mL}$ for cloxacillin. Penicillin, cloxacillin or first-generation cephalosporins are usually preferred because of their lower cost, more reliable bactericidal activity and reduced propensity to cause $C$ difficile-associated colitis. Strains of $S$ aureus that are resistant to methicillin will also be resistant to clindamycin, while erythromycin-resistant strains have a tendency to acquire clindamycin resistance during therapy. In such settings, clindamycin is not recommended.

Levine et al (7), in the evidence-based publication Drugs of Choice, recommended topical clindamycin for moderate to severe acne vulgaris, and oral clindamycin as an alternative to the penicillins and cephalosporins for cellulitis and furunculosis in patients with drug allergies. (These constitute level 3 evidence.)

The Ontario Anti-infective Review Panel consultants (8), in the Ontario Ministry of Health-sanctioned Anti-Infective Guidelines for Community-Acquired Infections, listed the indications for clindamycin as alternative therapy for impetigo and bullous impetigo in adults and children; alternative for uncomplicated cutaneous abscesses and complicated carbuncles; preferred therapy or alternative for complicated and decubitus ulcers; alternative for human bites; and preferred therapy for perirectal and perianal abscesses. It was considered an alternative therapy for severe but uncomplicated nonfacial cellulitis, preferred therapy or alternative for diabetic foot cellulitis (according to severity, see below), and a preferred therapy for invasive group A streptococcal infections. In the re- 
cently published second edition of the Anti-infective Guidelines for Community-acquired Infections, similar indications were presented (9). (These recommendations constitute level 3 evidence.)

Few randomized studies of clindamycin used to treat skin and soft tissue infections exist. In a relatively large study of 240 children with streptococcal or staphylococcal skin infections, clindamycin was found to be equivalent to erythromycin and slightly superior to penicillin, with no evident adverse effects. Assessment of efficacy at seven days yielded successful treatment in $97 \%$ of those treated with clindamycin, $99 \%$ of those treated with erythromycin and $91 \%$ of those treated with penicillin. The rates were $97 \%$ to $99 \%$ at 14 days for all three regimens (10).

Skin and soft tissue infections in diabetic patients and necrotizing fasciitis due to group A streptococcus pyogenes are distinct and more severe types of soft tissue infections, and will be discussed separately below.

In conclusion, clindamycin is a safe and effective alternative for the treatment of skin and soft tissue infections (level 1 evidence for efficacy). Cloxacillin, penicillin and first-generation cephalosporins are usually preferred due to their much lower cost, narrower spectrum of activity and better side effect profile.

Necrotizing fasciitis: Subtherapeutic amounts of clindamycin may have activity against toxin production by $S$ aureus and toxin-producing streptococci. In in vitro and animal models, clindamycin decreases toxin production in necrotizing fasciitis caused by invasive group A streptococci. Consequently, despite the lack of human data, many experts recommend the combination of clindamycin and penicillin for severe group A infections such as necrotizing fasciitis. Clindamycin is recommended for this indication in Anti-Infective Guidelines for Community-Acquired Infections as a first-line agent, together with penicillin $(8,9)$. Falagas and Gorbach $(3)$, in a recent review, recommended clindamycin together with penicillin for severe skin and soft tissue infections due to group A streptococci or Clostridium perfringens.

In conclusion, clindamycin and penicillin should be used together for severe streptococcal and possibly clostridial soft tissue infections (level 3 evidence, expert opinion). Given the rarity of these infections and their severe sequelae, combined therapy is the treatment of choice.

Diabetic foot: In a recent position paper by the Committee on Antimicrobial Agents and Fong (11), clindamycin was listed as an alternative for the treatment of mild, moderate and severe diabetic foot infections. Cloxacillin and cephalexin were preferred for mild infection, while amoxicillin with clavulinic acid and cotrimoxazole with metronidazole were preferred for moderate infection. Except for mild infections, clindamycin should be combined with another antibiotic: with cotrimoxazole, ciprofloxacin, or ofloxacin for moderate infections, and with an aminoglycoside for severe infections.

In the Anti-Infective Guidelines for Community-Acquired Infections, the consensus of experts recommended clindamycin as preferred treatment (usually together with ciprofloxacin) for severe diabetic foot infections and as an alternative therapy for milder infections $(8,9)$. Falagas and Gorbach (3) also recommended clindamycin with a quinolone antibiotic for diabetic feet and decubitus ulcers.

Two primary studies specifically addressed the issue of clindamycin in diabetic foot infections. One, a nonrandomized study of oral clindamycin and ciprofloxacin therapy compared with in-hospital regimens, claimed to show a major cost saving with equally effective oral therapy (12). Therapy was subsequently withdrawn due to "significant irregularities ... in ... execution and analysis" and "false data" (13). No useful inference can be made from these data. In a second study, 56 prospective diabetic patients with nonlimb-threatening cellulitis were randomized to cephalexin or clindamycin four times daily for 14 days (14). They were also treated with debridement and local therapy. Rates of clinical and microbiological cure were similar with either antibiotic, approximately $90 \%$. There were five treatment failures, one of which was in the clindamycin group (not significant). Three of these responded to further out-patient antibiotics, and two required intravenous antibiotics. This study showed that cephalexin was as effective as clindamycin for mild-to-moderate diabetic foot infections and that both were well tolerated.

In conclusion, clindamycin is indicated as preferred or alternative therapy for diabetic foot infections, based on level 1 evidence (for equivalence) in mild to moderate infection and level 3 evidence (expert opinion) for moderate to severe infection.

\section{OSTEOMYELITIS AND SEPTIC ARTHRITIS}

Falagas and Gorbach (3) recommended clindamycin for the treatment of osteomyelitis due to $S$ aureus and anaerobes, particularly if associated with diabetes or decubitus ulcers. Steigbigel (1) recognized that clindamycin is effective for many of the organisms that cause osteomyelitis, and achieves drug concentrates in bone, but states that there is "no established advantage for osteomyelitis".

No comparative studies for clindamycin versus alternative regimens were found. Clindamycin was effective for septic arthritis or osteomyelitis in an open study of 48 children, who were treated with a regimen of intravenous administration until afebrile for three days, followed by oral medication for one week (cellulitis) or up to six months (chronic osteomyelitis) (15).

In conclusion, clindamycin is an alternative to penicillin and cephalosporin derivatives for the treatment of osteomyelitis and septic arthritis (level 3 evidence, case series), and may be the drug of choice in combination with a quinolone for diabetic osteomyelitis (level 3 evidence, expert opinion).

\section{HEAD AND NECK INFECTIONS}

Head and neck infections, such as acute sinusitis, otitis media or pharyngitis, are usually caused by aerobic or facultatively anaerobic respiratory flora such as $S$ pneumoniae, $S$ aureus, Haemophilus influenza or group A streptococci. Chronic infections may include aerobes and anaerobes, and clindamycin may have a role in the therapy of these infections.

Clindamycin is an alternative to penicillin for treatment of dental abscesses (7). Indications include allergy, failure of penicillin treatment or immune-compromised status. Clinda- 
mycin is an alternative to amoxicillin, cephalexin, azithromycin or clarithromycin for the prophylaxis of bacterial endocarditis in patients undergoing dental procedures. For recurrent tonsillitis, clindamycin may be indicated (1), although reviewers remain concerned about its potential for inducing $C$ difficile-associated diarrhea and for inducing erythromycin or clindamycin-resistant pneumococci.

A small but clinically important and statistically significant study of 45 patients with recurrent group A streptococcal pharyngitis showed a major reduction of relapse rates and subsequent tonsillectomy with a 10-day course of clindamycin versus erythromycin or penicillin (16). Only two of 15 patients treated with penicillin, versus 14 of 15 with clindamycin, had eradication of their carrier status. Twelve of those treated with penicillin had recurrent episodes, versus only one of 15 treated with clindamycin. A total of six patients underwent tonsillectomy: four of these had been treated with penicillin, and two had received erythromycin. No patient treated with clindamycin subsequently underwent tonsillectomy. Clindamycin may be considered for chronic sinusitis or chronic otitis media (17), which may be caused by anaerobes, and is an alternative treatment for eradicating Corynebacterium diphtheriae carriage (3).

In conclusion, clindamycin is an alternative for treatment of several head and neck infections, including dental infections, recurrent pharyngitis and chronic sinusitis. The indications for its use in these conditions remains largely undefined, although level 1 evidence exists for its efficacy in preventing recurrence and tonsillectomy in patients with recurrent group A streptococcal pharyngitis.

\section{PREOPERATIVE PROPHYLAXIS}

For preoperative prophylaxis of head and neck cancers, which may be associated with mixed aerobic and anaerobic postoperative surgical site infections, clindamycin has been compared with cefazolin (18) and with ampicillin-sulbactam (19). In a randomized trial of 100 patients, $24 \mathrm{~h}$ of perioperative clindamycin or cefazolin resulted in a postoperative surgical site infection rate after flap reconstruction of $20 \%$ versus $22 \%$ respectively (not significant). No antibiotic toxicity was identified. Clindamycin was compared with ampicillin-sulbactam in 212 patients undergoing head and neck surgery, with 29 infections identified in those treated with clindamycin, versus 14 infections in those treated with ampicillin-sulbactam. There was a concomitant reduction of Gram-negative isolates in the latter group, and the authors argue for the inclusion of Gram-negative coverage in this type of surgery.

Clindamycin and cephalothin were compared in 263 adult patients undergoing cardiac surgery (20). Rates of wound infection were $3.2 \%$ and $6.5 \%$ for the clindamycin and cephalothin groups, respectively (not significant), with no cases of endocarditis. For pacemaker implantation, $48 \mathrm{~h}$ of flucloxacillin (or clindamycin in those who were allergic) was compared with placebo in a randomized trial of 473 patients undergoing first-ever permanent pacemaker placement (21). All nine serious infections occurred among those in the placebo group.

Abdominal prophylaxis studies were often studies of early treatment of intra-abdominal sepsis and will be discussed below under abdominal infections.

In conclusion, clindamycin used for one to nine doses perioperatively is effective in reducing the rate of postoperative infection, with an efficacy similar to that of cefazolin and cephalothin.

\section{PNEUMONIA}

Clindamycin is indicated for pleuropulmonary infections including aspiration pneumonia, lung abscess and empyema, unless due to aerobic Gram-negative organisms. Levine et al (7) considered clindamycin an alternative, in combination with ciprofloxacin, for the treatment of nursing home acquired pneumonia. The Ontario Anti-infective Review Panel $(8,9)$ also considered clindamycin and ciprofloxacin as alternatives for severe nursing home pneumonia.

A small study of clindamycin versus metronidazole in patients with proven anaerobic pulmonary infection found clindamycin to be clearly superior (22). Despite randomizing only 17 patients, two of seven patients on metronidazole versus nine of nine on clindamycin were cured. One patient on clindamycin died of massive aspiration. Despite the small numbers, these results were highly significant, and the baseline characteristics of the patients were more severe for those randomized to clindamycin.

A slightly larger study of 37 patients with lung abscess or necrotizing pneumonia randomized patients to clindamycin or penicillin for a minimum of eight days of intravenous and a total of four weeks of therapy (23). Of those taking penicillin, eight of 18 failed therapy, versus only one of 19 on clindamycin. Many of the penicillin failures were attributed to penicillin-resistant Bacteroides species.

Thus, clindamycin is probably the therapy of choice for anaerobic necrotizing pneumonia and aspiration pneumonia. Whether other antibiotics, such as amoxicillin-clavulinate, are comparable or superior is unknown.

\section{ABDOMINAL INFECTIONS AND PREOPERATIVE PROPHYLAXIS}

Reviewers consider clindamycin the antibiotic of choice (usually combined with an aminoglycoside) for the treatment of intra-abdominal infection (3). Initially, the role of anaerobes in abdominal abscess was demonstrated by the reduced incidence of such complications in regimens, which included clindamycin. Subsequently, the equal efficacy of clindamycin, metronidazole, cefoxitin and other antibiotics, in appropriate combination with Gram-negative agents, such as aminoglycosides, was demonstrated (24).

In a study of antibiotic 'prophylaxis' for wound infection after appendectomy (25), clindamycin was compared with cefazolin or placebo in 250 patients. The wound infection rate was reduced by clindamycin but not cefazolin, although more advanced cases with higher rates of perforated or gangrenous appendices were allocated to the cefazolin group. Rates of infection were $33 \%$ in the placebo arm, $17 \%$ in the clindamycin arm and 35\% in the cefazolin arm.

In a Canadian study of intra-abdominal sepsis, patients 
were treated with gentamicin and randomized to clindamycin or metronidazole (26). In 141 patients, rates of cure or improvement were $94 \%$ versus $96 \%$ for the metronidazole and clindamycin groups, respectively. Diarrhea occurred in six patients on metronidazole and three patients on clindamycin. All three patients with rash were in the clindamycin group. A greater number of patients treated with clindamycin developed abnormal liver function tests; however, these abnormalities did not necessitate changes in therapy.

For perforated appendicitis, clindamycin and gentamicin were similar in efficacy to cefoxitin (27). Similarly, clindamycin with tobramycin was similar to monotherapy with moxalactam for patients with secondary peritonitis (28), and meropenem was similar to tobramycin with clindamycin for advanced appendicitis (29). Imipenem was slightly better than clindamycin and tobramycin in a study of 290 patients (162 evaluable) for severe intra-abdominal infection (30). Results were corrected in multivariate analysis for APACHE II score, which was the strongest single predictor of therapeutic failure. The difference between the regimens was quite small, however, and may vary with local antibiotic resistance patterns.

In conclusion, clindamycin combined with an aminoglycoside is an alternative to a metronidazole and aminoglycoside combination, or other single agents with aerobic and anaerobic antibacterial activity for both the prophylaxis and treatment of intra-abdominal infection. Regimens containing metronidazole in combination with another agent that provides aerobic Gram-negative coverage are generally preferred due to equal efficacy, lower costs and reduced rates of $C$ difficile colitis.

\section{GYNECOLOGICAL INFECTIONS}

Clindamycin is indicated for the treatment of pelvic infections including pelvic inflammatory disease, pelvic abscesses, endometritis and bacterial vaginosis $(3,30,31)$. It has been used in pregnancy, and is classified as fetal risk factor B. There are no reports of congenital defects or other fetal toxicity (31). It crosses the placenta and is present in breast milk.

For all but bacterial vaginosis, it is usually combined with an aminoglycoside. Separate coverage for $C$ trachomatis is not required because clindamycin has activity against this organism. Early cohort studies showed that the addition of clindamycin to regimens consisting of penicillin and gentamicin decreased the rate of abscess formation.

No comparative studies exist of clindamycin versus metronidazole for pelvic infections. Similar regimens to those employed for abdominal infections generally are effective, except that doxycycline is often added if clindamycin is not part of the treatment regimen for pelvic inflammatory disease and other conditions in which $C$ trachomatis may be present. A study of ampicillin-sulbactam, cefoxitin and doxycycline, or clindamycin and gentamicin for pelvic inflammatory disease or endometritis found all regimens had similar efficacy (32).

Clindamycin is an alternative to erythromycin for the treatment of $C$ trachomatis cervicitis in pregnancy (33). Of 126 patients randomized to clindamycin $450 \mathrm{mg}$ qid or erythromycin $333 \mathrm{mg}$ qid, each for 14 days or to placebo, short term eradication was achieved in $93 \%$ versus $84 \%$ of clindamycin- or erythromycin-treated patients (not significant). At term, $12 \%$ of clindamycin-treated patients, $21 \%$ of erythromycin-treated and $43 \%$ of placebo-treated patients were culture-positive for $C$ trachomatis. Clindamycin was better tolerated than erythromycin, and side effects (predominantly gastrointestinal) were less common (10\% versus $23 \%$ ) than with erythromycin. Failure of treatment was associated with poor compliance.

Clindamycin, in an oral dose or as a vaginal gel, is effective for the treatment of bacterial vaginosis in both pregnant and non-pregnant patients $(3,34-37)$. In addition to its efficacy in eradicating symptomatic bacterial vaginosis, it may improve pregnancy outcome. Bacterial vaginosis has been correlated with premature labour (38), although the studies of the efficacy of treatment in prolonging gestation are contradictory. In a randomized study of 103 pregnant women with bacterial vaginosis and premature labour, clindamycin was more effective than placebo in prolonging gestation (36 days versus 19 days), with a nonsignificant increase in birth weight (39). In Indonesia a larger study of intravaginal gel, however, was unable to demonstrate any effect on rates of premature labour or low birth weight babies among 681 women treated in midtrimester (40). A recent randomized study demonstrated the safety and efficacy of metronidazole with erythromycin versus placebo in pregnant women with bacterial vaginosis. Preterm labour was significantly reduced in the treated group (41). Thus, metronidazole with or without erythromycin should be considered the preferred treatment of bacterial vaginosis in pregnancy.

There is level 1 evidence for clindamycin as a preferred or alternative therapy for pelvic infections, and as alternative therapy for bacterial vaginosis (after metronidazole) and $C$ trachomatis in pregnancy (after erythromycin and amoxicillin).

\section{OTHER INFECTIONS: PROTOZOA}

Clindamycin has been used in randomized trials for the treatment of Pneumocystis carinii pneumonia in HIV-infected patients. No difference in efficacy among trimethoprim/sulfamethoxazole, trimethoprim/dapsone, and clindamycin/primaquine was found in ACTG trial 108 (42). However, hematological toxicity was more common with the clindamycin/ primaquine regimen.

Clindamycin has also been studied for use against toxoplasmosis, particularly for ophthalmitis (43). For cerebral toxoplasmosis, case reports suggest clindamycin is effective (44), although the pharmacokinetic properties of poor distribution in the central nervous system should temper the enthusiasm for this approach until the effectiveness is demonstrated in clinical trials. Malaria (45) and babesiosis (46) have been treated with clindamycin, in combination with quinine sulphate.

In conclusion, clindamycin combined with primaquine is an accepted and effective alternative in the treatment of $P$ carinii pneumonia (level 1 evidence). Experience with its use in toxoplasmosis and malaria remains limited (level 3).

\section{ADVERSE EFFECTS OF CLINDAMYCIN}

Common side effects of clindamycin use include rash, hepatotoxicity and diarrhea. Nuisance side effects include nausea, anorexia, vomiting, flatulence and metallic taste (1-3). A 
mild-to-moderate morbilliform rash occurs in up to $10 \%$ of patients. All forms of clindamycin, including topical ointments, have been temporally related with $C$ difficile-associated diarrhea, including pseudomembranous colitis. While prompt antibiotic cessation, avoidance of antimotility agents and treatment with metronidazole or vancomycin will virtually always successfully treat this complication, hemicolectomy and fatalities may result. The incidence of $C$ difficile-associated diarrhea occurs with virtually all antibiotics, and the excess number of cases attributable to clindamycin is controversial. Nevertheless, some $0.1 \%$ to $10 \%$ of treatment courses will be complicated by this infection, and most authors feel that this complication is somewhat more common with clindamycin than with other antibiotics.

The overall rate of clinically significant diarrhea in patients with soft tissue infections may be very low, particularly in an out-patient setting. In a review of 15,019 out-patients treated for soft tissue infections conducted over five years in Leeds, United Kingdom, passive and active follow-up of all cases of severe diarrhea was undertaken (47). Thirteen patients developed diarrhea and two required hospitalization for pseudomembranous colitis. Both made an uneventful recovery (5).

The rate of acquiring $C$ difficile-associated diarrhea is much higher in in-patients. Although the Canadian MetronidazoleClindamycin Study Group (26) found similar rates of diarrhea in those treated with clindamycin (three cases) versus those treated with metronidazole (six cases), other investigators have found higher rates of $C$ difficile-associated diarrhea in patients treated with clindamycin. Gerding et al (48) randomized 156 patients to amikacin/metronidazole/placebo, amikacin/clindamycin/placebo, or amikacin/clindamycin/ampicillin. Efficacy was similar, whereas a higher rate of $C$ difficile diarrhea developed in those treated with clindamycin. In those who had no previous antibiotics, clindamycin-containing regimens were associated with a 30-day $C$ difficile acquisition rate of $31 \%$ versus $0 \%$ for the amikacin/metronidazole regimen.

Pear et al (49) reported a nosocomial epidemic of $C$ difficile-associated diarrhea that resolved only after restriction of clindamycin use by that hospital (49).

Thus, in conclusion, there is evidence from time series (level 3) and subgroup analyses of randomized studies (level 2) for the association of $C$ difficile-associated diarrhea and the use of clindamycin. These studies have shown rates of up to $30 \%$ acquisition of $C$ difficile-associated diarrhea by inpatients, compared with $0.1 \%$ severe diarrhea in out-patients. Where safer antibiotic regimens exist, such as the combination of an aminoglycoside with metronidazole for abdominal sepsis, such regimens are preferred.

\section{CONCLUSIONS}

Clindamycin is rarely the drug of choice for either Grampositive or anaerobic infections, with the exceptions of severe streptococcal cellulitis/fasciitis, diabetic foot and anaerobic lung infections. Reviewers classify clindamycin as the agent of choice for abdominal and pelvic infection, although cheaper and safer regimens exist that are often preferred. Nevertheless, clindamycin remains a valuable drug for allergic patients and for use against certain clearly defined syndromes. It is especially valuable for out-patients, but should be used sparingly in in-patients because of its association with $C$ difficile colonization and diarrhea.

Indications can be summarized as follows.

Clindamycin is an alternative to the penicillins and cephalosporins for the treatment of skin and soft tissue infections.

Clindamycin is the drug of choice, combined with penicillin, for severe group A streptococcal infection and possibly $C$ perfringens infections.

Clindamycin is the drug of choice for moderate to severe diabetic foot infections, usually combined with a quinolone, although cephalexin is equally effective for mild to moderate infections.

Clindamycin is an alternative to penicillins and cephalosporins for the treatment of septic arthritis and osteomyelitis, but is the drug of choice in diabetic osteomyelitis, combined with a quinolone.

Clindamycin is an alternative to penicillins for dental infections and endocarditis prophylaxis.

Clindamycin may be the treatment of choice for recurrent streptococcal pharyngitis/tonsillitis.

Clindamycin is the treatment of choice for anaerobic lung infections, including anaerobic lung abscess and necrotizing pneumonia.

Clindamycin may be employed as an alternative for treatment of intra-abdominal and pelvic infections.

Clindamycin is an alternative to erythromycin for the treatment of $C$ trachomatis in pregnancy.

Clindamycin is an alternative to metronidazole for the treatment of bacterial vaginosis.

Clindamycin is an alternative to trimethoprim/ sulfamethoxazole for the treatment of $P$ carinii pneumonia.

\section{REFERENCES}

1. Steigbigel NH. Macrolides and clindamycin. In: Mandell GL, Bennett JE, Dolin R, eds. Douglas and Bennett's Principles and Practice of Infectious Diseases. New York: Churchill Livingstone, 1995:334-6.

2. O'Hanley PD, Tam JY, Holodniy M. Infectious disorders. In: Melmon KL, Morrelli HF, Hoffman BB, Nierenberg DW, eds. Melmon and Morrelli's Clinical Pharmacology: Basic Principles in Therapeutics, 3rd edn. New York: McGraw-Hill, 1992:710.

3. Falagas ME, Gorbach SL. Clindamycin and metronidazole. Med Clin North Am 1995;79:845-67.

4. Klainer AS. Clindamycin. Med Clin North Am 1987;71:1169-75.

5. Gatti G, Flaherty J, Bubp J, White J, Borin M, Gambertoglio J. Comparative study of bioavailabilities and pharmacokinetics of clindamycin in healthy volunteers and patients with AIDS. Antimicrob Agent Chemother 1993;37:1137-43.

6. Nordbring F. Aspects of the clinical use of clindamycin. A summary. Scand J Infect Dis 1984;43(Suppl):89-90.

7. Levine M, Lexchin J, Pellizzari R, eds. Drugs of Choice. A Formulary for General Practice. Ottawa: Canadian Medical Association, 1995.

8. Ontario Anti-infective Review Panel. Anti-Infective Guidelines for Community-Acquired Infections. Toronto: Queen's Printer for Ontario, 1994. 
9. Ontario Anti-infective Review Panel. Anti-infective Guidelines for Community-Acquired Infections, 2nd edn. Toronto: Queen's Printer for Ontario, 1997.

10. Dillon HC, Derrick CW. Clinical experience with clindamycin hydrochloride: I. Treatment of streptococcal and mixed streptococcal-staphylococcal skin infections. Pediatrics $1975 ; 55: 205-12$

11. Committee on Antimicrobial Agents, Fong IW. Management of diabetic foot infection: A position paper. Can J Infect Dis 1996; 7:361-5

12. Sesin GP, Paszko A, O'Keefe E. Oral clindamycin and ciprofloxacin therapy for diabetic foot infections. Pharmacotherapy 1990;10:154-6.

13. Scheife RT. Oral clindamycin and ciprofloxacin therapy for diabetic foot infections: A retraction. Pharmacotherapy 1990;110:261.

14. Lipsky BA, Pecoraro RE, Larson SA, Hanley ME, Ahroni JH. Outpatient management of uncomplicated lower-extremity infections in diabetic patients. Arch Intern Med 1990;150:790-7.

15. Feigin RD, Pickering LK, Anderson D, Keeney RE, Shackleford PG. Clindamycin treatment of osteomyelitis and septic arthritis in children. Pediatrics 1975;55:213-23.

16. Brook I, Hirokama R. Treatment of patients with a history of recurrent tonsillitis due to group A beta-hemolytic streptococci. A prospective randomized study comparing penicillin, erythromycin, and clindamycin. Clin Pediatr 1985;24:331-6.

17. Brook I, Yocum P. Antimicrobial management of chronic sinusitis in children. J Laryngol Otol 1995;109:1159-62.

18. Johnson JT, Wagner RL, Schuller DE, Gluckman J, Suen JY, Snyderman N. Prophylactic antibiotics for head and neck surgery with flap reconstruction. Arch Otolaryngol Head Neck Surg 1992;118:488-90.

19. Weber RS, Raad I, Frankenthaler R, et al. Ampicillin-sulbactam versus clindamycin in head and neck oncologic surgery. The need for Gram-negative coverage. Arch Otolaryngol Head Neck Surg 1992;118:1159-63.

20. Pien FD, Michael NL, Mamiya R, et al. Comparative study of prophylactic antibiotics in cardiac surgery. Clindamycin versus cephalothin. J Thor Cardiovasc Surg 1979;77:908-13.

21. Mounsey JP, Griffith MJ, Tynan M, et al. Antibiotic prophylaxis in permanent pacemaker implantation: A prospective randomized trial. Br Heart J 1994;72:339-43.

22. Perlino CA. Metronidazole vs clindamycin treatment of anaerobic pulmonary infection. Failure of metronidazole therapy. Arch Intern Med 1981;141:1424-7.

23. Gudiol F, Manresa F, Pallares R, et al. Clindamycin vs penicillin for anaerobic lung infections. High rate of penicillin failures associated with penicillin-resistant Bacteroides melaninogenicus. Arch Intern Med 1990;150:2525-9.

24. Donovan IA, Ellis D, Gatehouse D, et al. One-dose antibiotic prophylaxis against wound infection after appendicectomy: a randomized trial of clindamycin, cefazolin sodium, and a placebo. Br J Surg 1979;66:193-6.

25. Prospective, randomized comparison of metronidazole and clindamycin, each with gentamicin, for the treatment of serious intra-abdominal infection. Surgery 1983;93:221-9.

26. Meller JL, Reyes HM, Loeff DS, Federer L, Hall JR. One-drug versus two-drug antibiotic therapy in pediatric perforated appendicitis: a prospective randomized study. Surgery 1991;110:764-8.

27. Stellato TA, Danziger LH, Hau T, Gauderer MWL, Ferron JL, Gordon N. Moxalactam versus tobramycin-clindamycin. A randomized trial in secondary peritonitis. Arch Surg 1988; $123: 714-7$

28. Berne TV, Yellin AE, Appleman MD, Heseltine PN, Gill MA. Meropenem versus tobramycin with clindamycin in the antibiotic management of patients with advanced appendicitis. J Am Coll Surg 1996;182:403-7.

29. Solomkin JS, Dellinger EP, Christou NV, Busuttil RW. Results of a multicenter trial comparing imipenem/cilastin to tobramycin/ clindamycin for intra-abdominal infections. Ann Surg 1990;212:581-91.

30. Gorbach SL. Current experience with clindamycin in the treatment of abdominal and female pelvic infections. Scand J Infect Dis 1984;43(Suppl):82-8.

31. Hammill HA. Metronidazole, clindamycin, and quinolones. Obstet Gynecol Clin North Am 1989;16:317-29.

32. McGregor JA, Crombleholme WR, Newton E, Sweet RL, Tuomala $\mathrm{R}$, Gibbs RS. Randomized comparison of ampicillin-sulbactam to cefoxitin and doxycycline or clindamycin and gentamicin in the treatment of pelvic inflammatory disease or endometritis. Obstet Gynecol 1994;83:998-1004.

33. Alger LS, Lovchik JC. Comparative efficacy of clindamycin versus erythromycin in eradication of antenatal Chlamydia trachomatis. Am J Obstet Gynecol 1991;165:375-81.

34. Sweet RL. New approaches for the treatment of bacterial vaginosis. Am J Obstet Gynecol 1993;169:479-82.

35. Fischbach F, Petersen EE, Weissenbacher ER, Martius J, Hosmann J, Mayer H. Efficacy of clindamycin vaginal cream versus oral metronidazole in the treatment of bacterial vaginosis. Obstet Gynecol 1993;82:405-10.

36. Ferris DG, Litaker MS, Woodward L, Mathis D, Hendrick J. Treatment of bacterial vaginosis: a comparison of oral metronidazole, metronidazole vaginal gel, and clindamycin vaginal cream. J Fam Pract 1995;41:443-9.

37. Schlicht JR. Treatment of bacterial vaginosis. Ann Pharmacother 1994;28:483-7.

38. Hillier SL, Nugent RP, Eschenbach DA, et al. Association between bacterial vaginosis and preterm delivery of a low-birth-weight infant. The Vaginal Infections and Prematurity Study Group. N Engl J Med 1995;333:1737-42.

39. McGregor JA, French JI, Seo K. Adjunctive clindamycin therapy for pre-term labour: results of a double-blind, placebo-controlled trial. Am J Obstet Gynecol 1991;165:867-75.

40. Joesoef MR, Hillier SL, Wiknjosastro G, et al. Intravagina clindamycin treatment for bacterial vaginosis: effects on pre-term delivery and low birth weight. Am J Obstet Gynecol 1995; 173:1527-31.

41. Hauth JC, Goldenberg RL, Andrews WW, DuBard MB, Copper RL. Reduced incidence of preterm delivery with metronidazole and erythromycin in women with bacterial vaginosis. $\mathrm{N}$ Engl J Med 1995;333:1732-6.

42. Safrin S, Finkelstein DM, Feinberg J, et al. Comparison of three regimens for treatment of mild to moderate Pneumocystis carinii pneumonia in patients with AIDS. A double-blind, randomized, trial of oral trimethoprim-sulfamethoxazole, dapsonetrimethoprim, and clindamycin-primaquine. Ann Intern Med 1996;124:792-802.

43. Rothova A, Meenken C, Buitenhuis HJ, et al. Therapy for ocular toxoplasmosis. Am J Ophthalmol 1993;115:517-23.

44. Luft BJ, Faner R, Korzun AH, Leport C, et al. Toxoplasmic encephalitis in patients with the acquired immunodeficiency syndrome. N Engl J Med 1993;329:995-1000.

45. Kremsner PG, Winkler S, Brandts C, Neifer S, Bienzle U, Graninger W. Clindamycin in combination with chloroquine or quinine is an effective therapy for uncomplicated Plasmodium falciparum malaria in children from Gabon. J Infect Dis 1994;169:467-70.

46. Herwaldt BL, Springs FE, Roberts PP, et al. Babesiosis in Wisconsin: a potentially fatal disease. Am J Trop Med Hyg 1995;53:146-51

47. Wilson DH. Clindamycin in the treatment of soft tissue infections: A review of 15,019 patients. Br J Surg 1980;67:93-6.

48. Gerding DN, Olson MM, Johnson S, Peterson LR, Lee JT. Clostridium difficile diarrhea and colonization after treatment with abdominal infection regimens containing clindamycin or metronidazole. Am J Surg 1990;159:212-7.

49. Pear SM, Williamson TH, Bettin KM, Gerding DN, Galgiani JN. Decrease in nosocomial Clostridium difficile-associated diarrhea by restricting clindamycin use. Ann Intern Med 1994;120:272-7. 


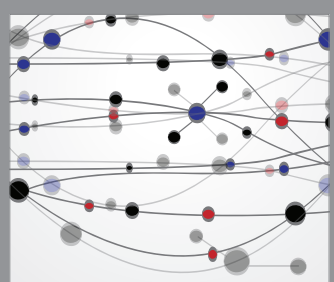

The Scientific World Journal
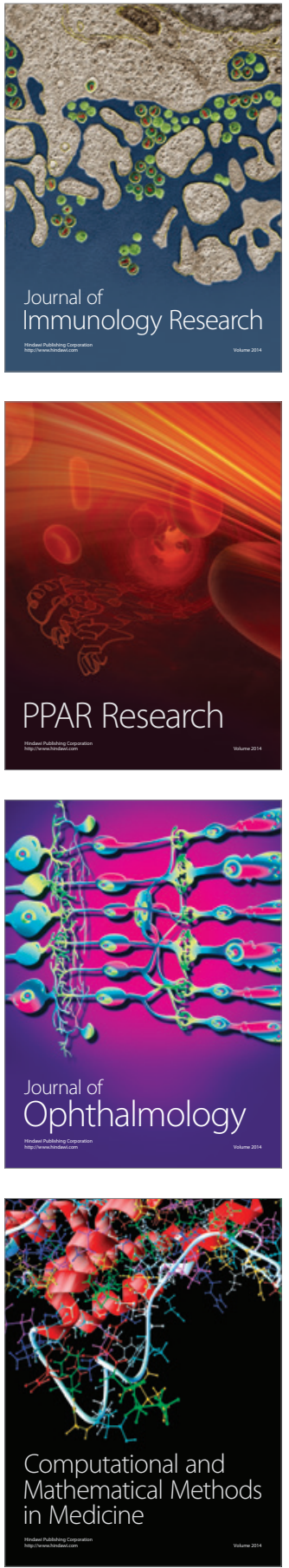

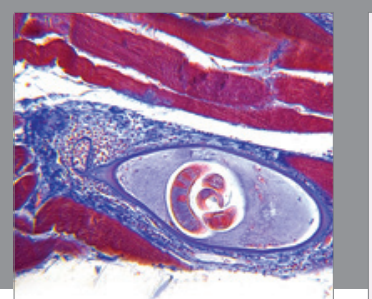

Gastroenterology Research and Practice

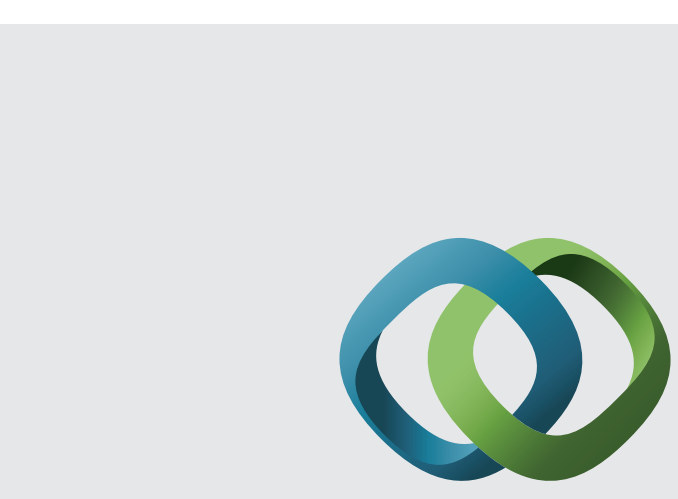

\section{Hindawi}

Submit your manuscripts at

http://www.hindawi.com
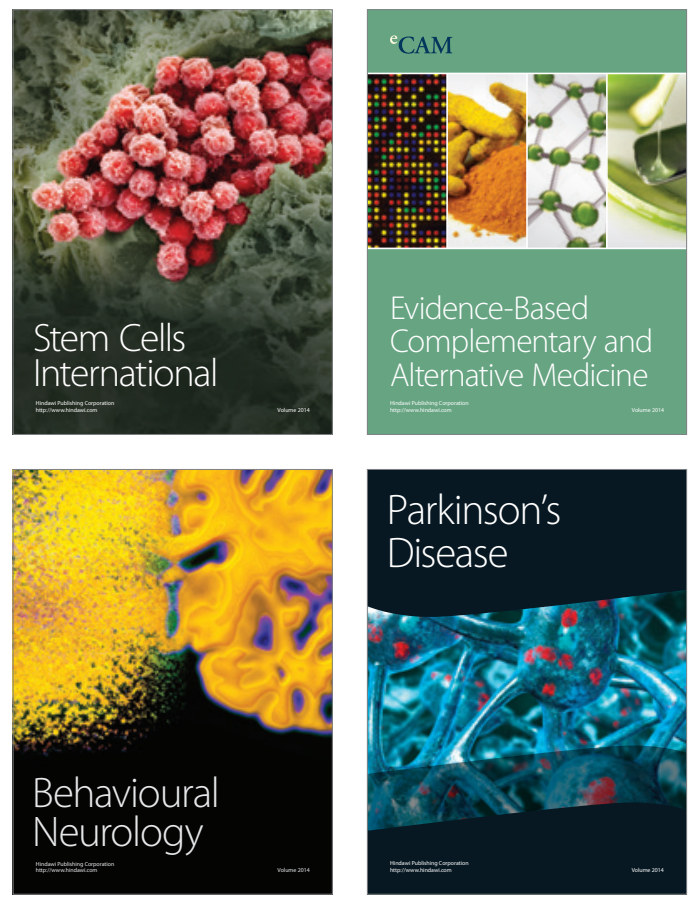
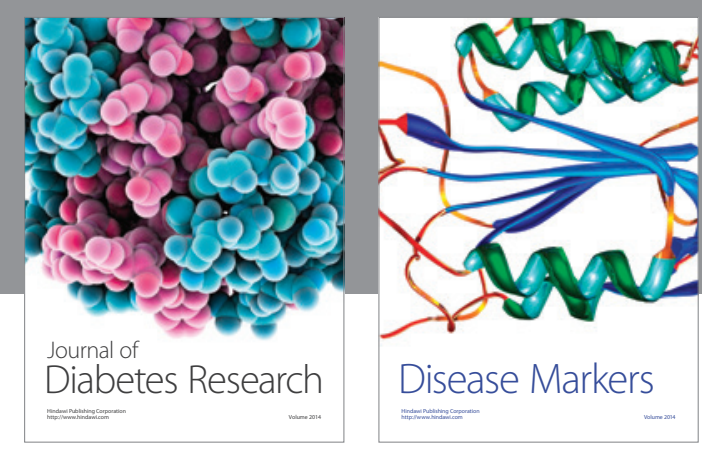

Disease Markers
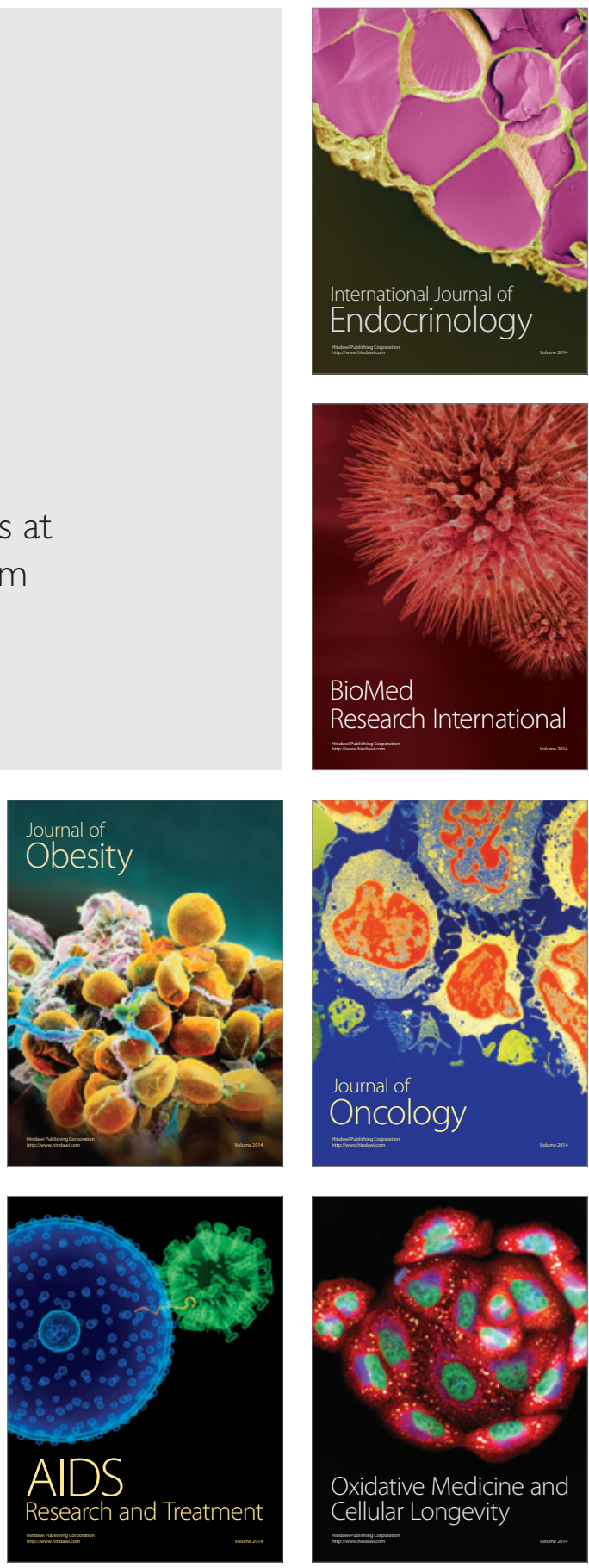